\title{
The Challenges of Creating Successful Collaborative Working and Learning Activities in Online Engineering Courses
}

\author{
Liz Bacon, PhD, and Lachlan MacKinnon, PhD \\ University of Greenwich, UK, e.bacon@gre.ac.uk, 1.mackinnon@gre.ac.uk
}

\begin{abstract}
The authors consider a number of the issues that arise when developing online engineering courses, with a particular focus on group-based collaborative working and learning. They argue that these issues are more difficult to address in STEM subjects, where there is an expectation that students will work with heavyweight processes, requiring significant sharing of expertise and resources, rather than the lighter weight processes experienced by open, discursive groups in other subject areas. The paper considers the history of collaborative and cooperative working and learning in computer supported environments, leading to the current models of online support for such activities. It identifies the key challenges and success factors when developing online learning courses, drawn from both the research and the authors' own experience. It considers the challenges of moving from face-toface to online learning, and how these have been addressed, before focusing more closely on collaborative learning, particularly in Engineering and related subjects. The authors then report on the experience of running a MOOC (Massively Open Online Course) for an $E U$ research project, in which they attempted to use a heavyweight Engineering Design process, Concurrent Design (CCD) to support collaborative activities within the course. The design and development of the course is described, and then the operation of the MOOC and the experience of the students and tutors, concluded by a statistical view of the outcomes. The paper then draws some conclusions for the design and development of online courses in Engineering, and a consideration of how to deal with preparing students to engage with heavyweight processes, like $C C D$, in such online courses. Techniques involving pre-selection, filtering and blended learning are discussed, and considerations of the motivation of students when undertaking courses as part of qualification studies. We must develop techniques to support collaborative learning in online courses, as they represent the future.
\end{abstract}

Keywords-Online learning, Collaborative, Cooperative, MOOCs

Digital Object Identifier

(DOI):http://dx.doi.org/10.18687/LACCEI2016.1.1.151

ISBN: 978-0-9822896-9-3

ISSN: 2414-6390

$14^{\text {th }}$ LACCEI International Multi-Conference for Engineering, Education, and Technology: "Engineering Innovations for Global Sustainability", 20-22 July 2016, San José, Costa Rica. 


\title{
The Challenges of Creating Successful Collaborative Working and Learning Activities in Online Engineering Courses
}

\author{
Liz Bacon, PhD, and Lachlan MacKinnon, PhD \\ University of Greenwich, UK, e.bacon@gre.ac.uk,l.mackinnon@gre.ac.uk
}

\begin{abstract}
The authors consider a number of the issues that arise when developing online engineering courses, with a particular focus on group-based collaborative working and learning. They argue that these issues are more difficult to address in STEM subjects, where there is an expectation that students will work with heavyweight processes, requiring significant sharing of expertise and resources, rather than the lighter weight processes experienced by open, discursive groups in other subject areas. The paper considers the history of collaborative and cooperative working and learning in computer supported environments, leading to the current models of online support for such activities. It identifies the key challenges and success factors when developing online learning courses, drawn from both the research and the authors' own experience. It considers the challenges of moving from face-to-face to online learning, and how these have been addressed, before focusing more closely on collaborative learning, particularly in Engineering and related subjects. The authors then report on the experience of running a MOOC (Massively Open Online Course) for an EU research project, in which they attempted to use a heavyweight Engineering Design process, Concurrent Design (CCD) to support collaborative activities within the course. The design and development of the course is described, and then the operation of the MOOC and the experience of the students and tutors, concluded by a statistical view of the outcomes. The paper then draws some conclusions for the design and development of online courses in Engineering, and a consideration of how to deal with preparing students to engage with heavyweight processes, like $C C D$, in such online courses. Techniques involving pre-selection, filtering and blended learning are discussed, and considerations of the motivation of students when undertaking courses as part of qualification studies. We must develop techniques to support collaborative learning in online courses, as they represent the future.
\end{abstract}

\section{MOOCs}

Keywords-Online learning, Collaborative, Cooperative,

\section{INTRODUCTION}

There are a number of very good reasons for developing and providing online learning resources and support, both for students who physically attend classes, and those studying at a distance partially or completely online. The potential to provide a much more personalized learning experience, to offer different modes of explicative media, and, in many ways most importantly, to offer anytime-anywhere access to learning resources, are good academic reasons. Also, demand for higher education is exploding around the world and the nature of education is changing [1]. As reported by Unesco [2], between 1970 and 2007, the number of students in higher education increased from 28.6 million to 152.5 million. INTO
[3] has analyzed OECD data, and suggests that, "Within a decade, the demand for higher education will surpass 265 million. That is greater than the population of Nigeria or Russia”. However, as reported by WSJ [4] a lot more distance online education is required in future as countries simply cannot cope with the demand, to quote: "Consider India, which has 600 million people under the age of 25 and an outdated university system struggling to grow a workforce to support the third-largest economy in the world. An analysis a few years ago showed that, to address educational needs using traditional methods, India would need to build 1,500 campuses and-even more challenging-find qualified instructors to staff them".

From this, it should be clear that more online learning for all modes of study, from campus-based students through to pure distance students, is required. However, the nature of online learning is complex and there are many factors required for success. For example, one aspect of learning which has always been important, no matter the mode of delivery, is learning through social interaction [5]. In an online environment this is much more challenging, especially when people have never met each other face-to-face before. This is a key issue in STEM subjects, where there is a significant requirement for students to learn to work together in groups and teams, often utilizing heavyweight processes requiring the sharing of expert knowledge and resources. This kind of collaborative working is commonplace in engineering and science workplaces, and in the $1990 \mathrm{~s}$ gave rise to the Computer-Supported Collaborative Working (CSCW) movement [6], which has developed a wide range of tools and practices to support CSCW. The Computer-Supported Cooperative Learning (CSCL) movement [7] grew up alongside $\mathrm{CSCW}$, with a focus on how learning took place in online working teams, and in more recent years this has morphed into Computer-Supported Collaborative Learning [8]. However, the existence and history of these movements, combined with the tools and practices they have developed, does not in itself address the issue of motivating students to undertake collaborative, group-based activities, in either faceto-face or online learning. In order to address this issue, it is necessary to reevaluate the nature of collaboration in online learning and the complexities of undertaking this in engineering disciplines.

Digital Object Identifier (DOI): http://dx.doi.org/10.18687/LACCEI2016.1.1.151 ISBN: 978-0-9822896-9-3

ISSN: $2414-6390$

$14^{\text {th }}$ LACCEI International Multi-Conference for Engineering, Education, and Technology: "Engineering Innovations for Global Sustainability”, 20-22 July 2016, San José, Costa Rica. 
This paper discusses the factors required for success in online learning, focusing on collaboration as a key theme. It discusses the needs of online collaboration in engineering related disciplines and how these may differ from other subjects. Finally it reports on the results of a MOOC focused on collaborative learning and then draws some lessons from this for the future of online adult engineering education.

\section{CHALLENGES AND SUCCESSES IN ONLINE LEARNING}

This section focuses on a review of the literature around success factors for online learning, online collaboration and the differences between face-to-face and online learning.

\section{A. Factors for success in online learning}

Typical success rates in online distance learning modes of study tend to have lower success rates than when some faceto-face interaction is involved. There are a variety of reasons for this such as those cited by MacKinnon and Bacon [9] and Hachey et al. [10], some of which the educator cannot influence.

1. Prior experience of online courses - tends to indicate a person is more likely to succeed.

2. Age - older people tend to be more successful

3. Gender - women tend to be more successful than men

4. Ethnicity - white students tend to be more successful than BME students for example.

5. Motivation - motivation is critical to success, as has been demonstrated by the generally poor success rates of MOOCs, which typically have a low commitment threshold for sign up.

6. Intrinsic interest in the subject - is linked to, and likely to drive, aspects of motivation

7. Personal and financial issues - to be successful with study people have to be in the right frame of mind, and dealing with personal issues can impact time available for, and emotional commitment to, learning.

8. Social and cultural characteristics including an ability to make friends online - some people find this easier online than others.

9. Learning styles and learning strategies - whilst the concept of learning styles is still under debate, although many would argue they do exist [11], people find ways to learn, and whether compatible with their learning style or not, they develop learning strategies to help them make the most of learning materials presented to them in different forms [12].

10. Metacognition - this is the ability someone has to understand how they personally learn and is heavily tied up with the development of learning strategies. The issue for most people today is that they have been taught using traditional classroom techniques and have little experience of online learning. As every level of education is going through a similar transition at the same time to maximise the use of online learning, this position is likely to change in future. As the integration of online learning with face-to-face learning becomes a normal part of education from a young age, people will develop online learning strategies that work for them for both online as well as face-to-face learning.

11. Engaging and immersive learning environments are important to support motivation and interest, such as the use of games-based learning.

12. Provision of adaptive interfaces and personalisation of the environment including the learning materials

13. Ability to support students in forming social groups for mutual support and collaborative learning. This is affected by past experiences and the quality of the interaction etc. [13].

14. Retention of some physical contact with other staff and students, i.e. mode of delivery being more blended learning than completely online at a distance.

B. Challenges of moving from face-to-face to online education

Moving to use only, or simply more, online learning, requires a new set of skills for both the teacher and the student. Online learning is not about taking what we do faceto-face and repeating the pedagogy - that strategy tends to result in a poor version of what happens in the classroom [14]. An example of this was the use of virtual learning environments (VLEs), most teachers started by uploading their face-to-face teaching materials on to the VLE. No doubt a useful reference for students and a way to deliver materials to students but it did not come with a different approach to teaching and learning, and hence the term shovelware [15] was coined. This led many to view online learning as second rate, and it also tended to result in poorer success rates. The move to online learning should be about doing things differently and taking advantage of new possibilities such as the use of multimedia to provide multimodal versions of the same information. However, it isn't just about new possibilities, it also offers choice and personalisation in how to learn and the materials used. In other words, less of a one size fits all approach. It is also about not throwing away the things that we know support effective learning, such as socialisation and collaboration.

Online learning can however prove to be a confusing environment for students who are not familiar with the type of choices available to them, may lack self-discipline and organisational skills, and are less metacognitive, i.e. they may be unclear how to learn online so they don't know how to make choices between learning objects if more than one approach is provided. Emotions can also affect learning [16]. Online learning can also make weak students appear weaker as they lack the structure and discipline of attending a class with a teacher who knows them personally and is emotionally engaged with their learning, providing support and pressure to

$14^{\text {th }}$ LACCEI International Multi-Conference for Engineering, Education, and Technology: "Engineering Innovations for 
perform. Whilst this is possible to some extent online, the more distant people seem, including a teacher, the less emotionally engaged people are likely to be, and this can affect retention and performance.

Another key difference in face-to-face vs. online learning environments is the delivery of an engaging and immersive environment, and this can be done in very different ways. In a face-to-face environment, a good teacher will engage students in the subject, find ways to explain concepts in different ways to struggling students, pick up on body language and confused expressions, and use these an indicator for the need to reinforce or repeat key points throughout a teaching session. It is however hard for one teacher, even with only a few students, to provide any form of personalisation in the education process. It might be possible outside of class in a one-to-one dialogue where an explanation can be adapted to a student's specific need but in general there is very limited oneto-one time in class to this. An online environment can be immersive and engaging in a different way through, for example, use of games, videos and simulations. It is however a relatively depersonalized experience in the sense that a tutor is at a distance and it can make it harder to inspire students using standard learning materials and teaching approaches. Online learning can however be better at providing an en-masse personalised experience [17], not as sophisticated as a teacher can provide one-to-one, but at a lower level, such as providing choice of learning materials.

A final key area of difference between online and face-to-face is that of online socialisation and communication. Many studies have shown that the use of social groups can be important to the success and retention of students [18]. Social groups provide mutual support, joint working, someone to ask for help other than the teacher, peer pressure, competition etc. This is a vital part of online learning (as it is for face-to-face) given isolation is a key issue affecting dropout rates. New models of online learning have emerged which emphasise the importance of socialisation, such as that introduced by the Minerva project [19] where students are physically co-located, but learning online with their tutors. Of course students will have different levels of comfort in socialising online which might be quite different to their ability to socialise in person [20]. Appropriate behaviour does need to be monitored as people are often less considerate to the feelings of others when they don't know people well [21], and therefore discussion forums etc. should be monitored for inappropriate behaviours, such as bullying.

\section{Collaborative learning}

Ever since computer-based learning became possible, researchers have investigated and experimented with online collaborative learning, starting with computer-assisted learning $(\mathrm{CAL})$ and Computer-Supported Cooperative Working (CSCW), a term first coined by Greif and Cashman at a workshop in 1984 [6]. CSCW focuses on how computer systems can support collaborative working and brings together a number of fields, including the psychological and social impact in online working. Of course both fields have developed in parallel with the development of ever more sophisticated and powerful computers, both undergoing a step change with the introduction of the Internet and the WorldWide-Web. Whilst CSCW is not specific to learning, there is clearly a link between the two although in the early years, the two research streams were quite separate [22]. The field of Computer-Supported Collaborative Learning (CSCL) emerged later, bringing together these two core disciplines. The term "Networked Learning" is often referred to in CSCL where collaborations are exclusively or primarily remote [23]. Wang, S.L. and Hwang [24] argue that although online CSCL tends to be very text based, lacking social context cues such as tone of voice, gestures or emotional expressions, it can however facilitate higher order cognitive processes and creation of new knowledge. As argued by Noroozi [25], it can provide a very effective tool to develop the ability to learn to argue, and it certainly has the capability to allow learners from all over the world to debate topics together. Potentially this brings greater breadth and diversity of opinion into the discussion, as opposed to the more typical classroom based debate, in which participation is restricted to those present. "Community is the vehicle through which online courses are the most effectively delivered, regardless of content" [26], and Paloff \& Pratt also suggest [27] that the specific pedagogical benefits of collaborative learning can include:

- Development of critical thinking skills.

- Co-creation of knowledge and meaning.

- Reflection.

- Transformative learning.

Brindley [13] argues that online collaboration can also lead to deeper learning, development of team working skills, and an increased sense of community, which is linked to increased satisfaction and retention. Meslec and Curşeu [28], discuss the impact of "group design features that increase the effectiveness of individual and collaborative learning in student groups". Their review of the literature, which focuses on the application of group roles as defined by Belbin [29] and whether balanced groups, with all nine roles present (e.g. coordinator, teamworker and resource investigator), perform better than unbalanced groups. Research to-date is inconclusive and has yielded mixed results citing a number of influencing factors such as the size of the group and team quality such as the quality of the personal team interactions within the group.

Cowley et al. [30], classify learner-learner interactions as a four stage continuum:

- "Communication - people 'talking', discussing."

$14^{\text {th }}$ LACCEI International Multi-Conference for Engineering, Education, and Technology: "Engineering Innovations for Global Sustainability", 20-22 July 2016, San José, Costa Rica. 
- Collaboration - people sharing ideas and working together (occasionally sharing resources) in a loose environment.

- Cooperation - people doing things together - but each may still have their own purpose.

- Community - people striving for a common purpose."

With communication and collaboration being the most common in learner-learner interactions. Brindley [13] notes the, "strategies employed in the course to both communicate the value of collaborative learning and to increase motivation to participate in the study groups", were:

1. "Transparency of expectations.

2. Clear instructions.

3. Appropriateness of task for group work.

4. Meaning-making/relevance.

5. Motivation for participation embedded in course design.

6. Readiness of learners for group work.

7. Timing of group formation.

8. Respect for the autonomy of learners.

9. Monitoring and feedback.

10. Sufficient time for the task."

Resulting in the following implications for practice:

1. "Facilitate learner readiness for group work and provide scaffolding to build skills.

2. Establish a healthy balance between structure (clarity of task) and learner autonomy (flexibility of task).

3. Nurture the establishment of learner relationships and sense of community.

4. Monitor group activities actively and closely.

5. Make the group task relevant for the learner.

6. Choose tasks that are best performed by a group.

7. Provide sufficient time."

Additionally, interaction can help engage students and support retention, having the potential to play a number of roles [31] such as:

1. "Getting a learner's attention.

2. Keeping learner's interest.

3. Transferring information.

4. Aiding in retention.

5. Sparking reflection.

6. Evaluation - both formative and summative."

There is however only so much an instructor can do to ensure successful collaboration, in that success in online collaboration is affected, as discussed above, not only by a range of factors such as motivation and personal circumstances but a general dislike by most students of group work for a variety of reasons such as:

- Loss of control - a student can no longer complete a task on their own.
- $\quad$ Lack of timely delivery by other group members.

- Different work ethic.

- Unequal contribution to the group effort.

- Different understanding of the topic and competence with the technology tools required for collaboration.

- Different strengths and weaknesses.

- Different understanding of the problem to be solved.

- Group members working at a different pace.

- Different levels of confidence in own abilities may influence engagement.

- Confidence in the abilities of others to deliver.

Added to this, we often try to provide students with diverse multicultural groups, which can bring additional challenges [32] such as "different communication skills, behavioural patterns and intercultural competences".

\section{Collaborative learning in Engineering and related disciplines}

Guzdial et al. [33] discuss the need for collaboration in the field of engineering, arguing "engineers must learn to interact with others, critique others' work, and accept criticism and alternative viewpoints." This is particularly important due to the nature of the problems engineers have to solve. They need to be creative, innovative thinkers and have the ability to undertake scientific analysis [34], especially required when clients are rarely able to specify precisely what they are seeking. They need to recognise a need, define the problem and objectives, collect information and data, generate and analyse different solutions and recommend the best one. All these skills can be significantly enhanced through group work utilising discussion and debate, as evidenced by Khazaal [35]. Additionally, in STEM subjects, there are a number of heavyweight development processes that require the creation of teams, to share ideas and technical expertise to produce solutions to complex technical problems that could not readily be resolved by individuals working alone.

There is a lack of clarity over the precise classification and types of group work that can be undertaken by students, however Weimer [36] provides a useful guide, identifying cooperative, collaborative, Problem-Based Learning (PBL), and Team-Based Learning (TBL). All have evolved from different practices and are different. Cooperative learning requires a team-based approach to solve a problem where everyone pulls their weight. Collaborative learning is where groups of students work together to deepen their understanding of a topic. In PBL, students learn about a topic through being given a problem to solve. TBL are semipermanent groups designed to help students engage with learning on a longer-term basis.

$14^{\text {th }}$ LACCEI International Multi-Conference for Engineering, Education, and Technology: "Engineering Innovations for 
In engineering and related disciplines, in higher education, all four approaches identified by Weimer are commonly used in group-work. In online learning, collaborative group learning is the easiest in that a group doesn't have to produce a solution as an output of the group work, however, for both cooperative and PBL group work, they do.

Solving problems online in groups, where a broadly equal contribution is required by all team members, requires:

- Excellent communication skills

- The ability to work at a similar pace so some don't get left behind

- The ability to identify the strengths of each team member and appropriate roles for each person

- Project management and leadership skills (for at least one member of the group)

- The ability to negotiate a division of work, perhaps having never even met the other group members in person

- The ability to articulate ideas in writing (typically), in a timely manner

- $\quad$ The ability to deal with more cultural diversity and approaches to generating solutions.

The research shows that the characteristics of the students, relative to the type of online learning and the demands it makes on them, will be a key factor in determining the success of an online course. MOOCs were originally established to attract audiences of experienced, metacognitive adult learners, who could successfully manage their own learning in a heutagogic environment, but the reality is that the majority of learners in MOOCs require considerably more support than envisaged in that model [37]. In our experience, open courses attract a wide range of learners, ranging from aspirational novices to experienced students, and as a result have to tailor the collaborative elements and expectations accordingly. Clearly, online courses that offer lightweight collaborative activities, of a discursive nature, that do not require timed or timely attendance and offer participants a shared experience of learning, can be open to all. However, as the requirement changes to expect participants to take on roles within the group [38], to expect regular participation at fixed times and for fixed durations, and to expect individual participants to take on responsibilities for learning and sharing with the group, the need to select and filter participants grows. Heavyweight processes, requiring the sharing of technical expertise and knowledge in a structured and agreed format, really require selection on the basis of prior experience, or selection based on known commitment and motivation. We can envisage a future mixed economy of online courses, where participants sign up to closed, selective courses to learn heavyweight processes, that they can then apply in more open courses, and a wide range of open courses using lightweight processes are available for participant selection. Figure 1 shows a simple graphical representation of the relationship between student characteristics and type of online course.

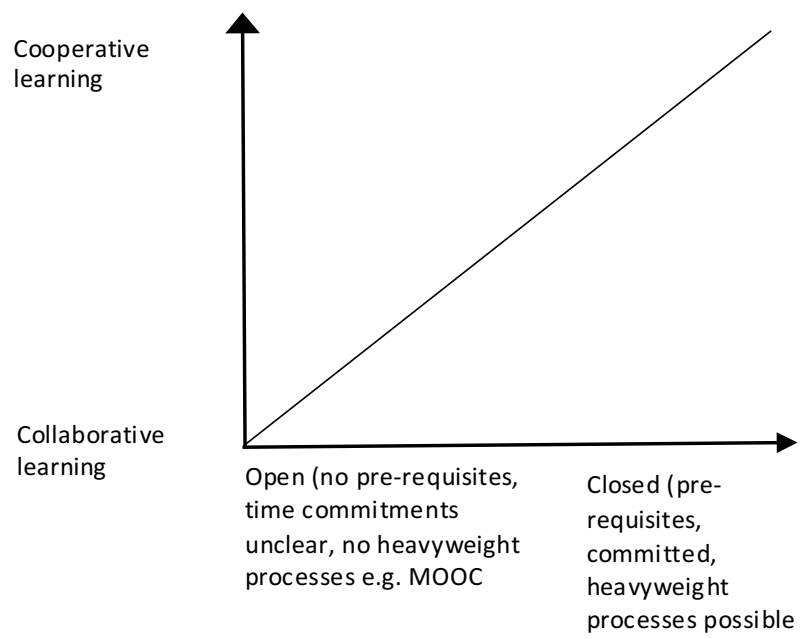

Figure 1: Graphical illustration of online course requirements

Teachonline in Canada [39] have published their analysis of current and future developments in online learning, and identify that "collaborative technologies and knowledge sharing will emerge as key resources for all forms of learning", as one of their key technology patterns. Whilst this may not seem a particularly surprising finding, it does once again highlight the importance of preparing our students to be effective collaborative learners.

In terms of MOOCs, the term GROOC has recently been defined, by Professor Mintzberg of McGill University [40], to describe group-oriented MOOCs, based on one he has developed on social activism. He also argues that there is no requirement to provide additional support to address group dynamics, stating that groups should be able to handle losing a few members and still function appropriately [41]. Whilst this might be true for collaborative learning, as discussed earlier, because no joint group output is required, i.e. it doesn't matter if all members of the group don't contribute equally or in a timely manner, or if some drop in or out, or others disappear, learning can still take place through dialogue and discussion. It probably also doesn't matter if some of the communication is not understood by all, or the composition of the group i.e. people can be randomly assigned to small groups and the particular strengths and weaknesses of individuals probably doesn't matter that much. However, if you are trying to achieve cooperative learning through a MOOC, which requires a group to jointly solve a problem, then the skills of the people in the group, the timeliness of their communication, their understanding of the problem etc. is critical to a successful outcome. The group may be able to sustain the loss of some members if it is large enough and those members are

$14^{\text {th }}$ LACCEI International Multi-Conference for Engineering, Education, and Technology: "Engineering Innovations for 
not assigned a critical role in the production of the joint output, but in general such losses are very damaging to cooperative learning groups. Whilst collaborative learning is important in engineering and related disciplines, cooperative learning is an absolute core requirement, and therefore the use of GROOCs or MOOCs can be particularly challenging in this context.

\section{LESSONS IN COOPERATIVE LEARNING IN THE DCCDFLITE MOOC}

This section describes the lessons learned from an EU project called dCCD-FLITE which was funded by the EU, through the Erasmus Lifelong Learning initiative, to support the demand for innovators and entrepreneurs, particularly in the IT sector as this area is seen as one of the most important for driving business innovation. There has also been a growing issue within the EU regarding the IT skills gap [42] and unemployment of the youth, and in some countries, for example the UK, unemployment of computer science graduates [43]. The target audience for the MOOC on entrepreneurship and innovation was a combination of IT professionals and IT higher education students, but the MOOC was open to all.

The structure of the MOOC course expected about 50 hours of student learning spread over an 8 -week period. This is longer than most MOOCs and although research tells us that this is a long time for a MOOC, and the longer the MOOC, the higher the dropout rate [44], it was necessary to complete all the requirements of the course. The MOOC course was broadly divided into two parts. The first 4 weeks were essentially focussed on learning the subject area and during the second four weeks students were asked to apply their knowledge in the production of a joint business plan and a short video, which could be used to pitch for funding to a relevant audience. Success factors in MOOCs and online learning have been fairly well analyse and a good summary of the issues is provided by Muilenburg and Berge [45] who identified eight factors for attrition in their study of over 1000 students, these were: academic skills, technical skills, learner motivation, time for studies, support studies, cost of internet connection, access to internet connection and technical problems. The shift from instructor led, to student led learning can also leave many students floundering as they lack the focussed structure of a traditional learning environment, and the support and guidance of a teacher, which can also lead to a high dropout rate.

A key aspect of this MOOC was innovation in the learning design process and being well aware of the challenges of group work in students who attend face-to-face classes, the team decided to adapt an approach called Concurrent Design (CCD), for utilisation in the distributed online environment called $(\mathrm{dCCD})$, in order to provide more structured support for online group work. CCD was originally developed by NASA [46], and is clearly suited to engineering type projects due to its origins. It was adapted for use in eLearning [47] during a previous project, and a distributed version of CCD, called $\mathrm{dCCD}$, was developed. $\mathrm{CCD}$ is "a systematic approach to integrated product development that emphasises the response to customer expectations. It embodies team values of cooperation, trust and sharing in such a manner that decision making is by consensus, involving all perspectives in parallel, from the beginning of the product life-cycle" [48]. It focuses on people (the experts with the knowledge to solve the problem,) the processes (what to do, when to do it etc.) and the tools to solve the problem e.g. project management tools. It follows a structured approach involving first of all analysing the situation, followed by a study of possibilities, a selection of appropriate solutions and then final choice. The sort of approach typically used in solving engineering problems but in this instance, is applied to both the approach to group working and to solving the problem, and was the first time that $\mathrm{dCCD}$ has been used as part of a group collaborative process in an online course.

Before the MOOC was run, the materials and approach were trialled with a few students in a pilot [48]. The feedback from the pilot was extremely valuable in designing the MOOC. One of the key messages from the students was to ensure a clearer distinction between domain content (entrepreneurship and innovation topics) vs. the processes to achieve the outcomes (CCD and Osterwalder Canvas). In terms of the learning design, the team were aware that group work would be the biggest challenge and within this there were two areas to focus on: the formation of the groups and then how they actually work together. An additional challenge in getting the groups to use the CCD process was that, whilst it is no doubt useful, it wasn't essential to the topic of entrepreneurship and innovation. Most students would have experienced successful group work in their life without the use of CCD and given the MOOC required a lot of student work, and entrepreneurship and innovation were the topics of interest, most students, understandably did not feel it necessary to put the time into learning how to apply CCD, it was simply easier to behave in group work how they had always done so.

With regard to formation of the groups, the biggest challenge is getting the students who want to complete the MOOC, into groups. Given the low threshold for MOOC sign up, many do not plan to engage fully with a MOOC and many don't even make it to the start of the course, $50 \%$ not being untypical [49]. This poses incredible challenges at the start given the instructors of a course cannot know into which category each student fits. However, in addition to needing to group students for a cooperative learning experience, in the second half of the course, the students needed to form groups to work on a specific business idea. Given about 1500 students

$14^{\text {th }}$ LACCEI International Multi-Conference for Engineering, Education, and Technology: "Engineering Innovations for 
registered for the course, allowing them all to have an online discussion with 1500 other students to form groups around a business idea would clearly be chaotic at best. A decision was therefore taken to randomly allocate students to groups, ask them to debate in their group if they could find a business idea which suited them and if not, change group or attempt to form their own etc. Despite numerous explanations to the students of the process, it took some time for them to understand the process. However one of the biggest challenges was advising students how long to wait for others in their group to respond given only about $50 \%$ of those who registered actually started the course, which is typical of a MOOC. Many hours were spent removing students from groups who had not engaged (note that they could put themselves back in a group if they were removed in error). The first four weeks were focused on trying to form groups whilst students worked through the learning materials. During that period many discussion forums were provided for debate on topics and the entire group used those. These worked reasonably well in aiding student learning and helping to deepen understanding but as this was collaborative learning not cooperative learning, it was not important who engaged or when.

For the cooperative, joint group work, ultimately no group managed to make a group submission however, those who did make a final submission as individuals worked as a loose group together critiquing each other's work and, judging by the comments and discussion, this was clearly a useful experience. In summary, 1556 registered to take the MOOC. Of those, 804 registered but never attended the course $(51.7 \%) .752$ attended at least once, 572 ceased using the MOOC after 3 weeks, A total of 152 were considered to be active at about week $6.57 \%$ of learners did not have English as their mother tongue and $48 \%$ of those who responded to our survey said they never had any intention of completing the MOOC at the start, they just wanted to e.g. dip in for some learning. As a result, the number of genuinely active students reduced further, with 12 submitting the personal business model, 9 submitting business plans [50].

\section{DISCUSSION, CONCLUSIONS AND FUTURE WORK IN ONLINE ENGINEERING EDUCATION}

Concurrent Design (CCD) has proven itself to be an excellent tool for collaborative use in engineering related disciplines however, it has not yet shown itself to be suitable in an online environment to support large scale learning. The major issue being the formation of groups in a MOOC, this is less of a challenge if the students are committed to study e.g. they have paid for a course and also if the number of students is smaller in that a tutor will have the capacity to nurture those groups if needed. CCD also has a high learning curve and may need practice before being applied to solve a real engineering problem online. Within a MOOC environment, given the complex and changing motivations of student towards the study, it may be appropriate to require students to have completed a short course on CCD first, but also to find a way to filter those at the start who are sufficiently keen to stay engaged throughout. Another challenge for our MOOC was finding a business idea that a group of students were prepared to work on. An idea was generally posed by one of the students within a group who genuinely wanted to launch a business, however it was hard for the student to explain the problem in sufficient depth for the other students to engage with it. Many also they had business ideas of their own that they wished to focus on. It is likely that a similar situation would occur with engineering problems and therefore it may be better to assign students problems to solve so students have a similar depth of understanding of the problem they are trying to solve and not allow them to work on their own ideas. This may of course lead to further attrition.

In terms of group work, it has been demonstrated that collaborative work, in the sense of discussion and debate to deepen thinking and understanding can work. For example Mackness et al. [51] formed groups by getting students to proactively put themselves forward to be placed in a group and then when there were a sufficient number to form a group, another one was started. In the MOOC described here, this approach would be unlikely to work for cooperative learning unless those students could have been enthused into working on one business idea and the evidence from the MOOC showed that to be unlikely.

Given the rapidly increasing global demand for higher education, and the inability of many countries to meet their local demand, it is inevitable that, due to cost, the demand for online education will increase and the mass market of MOOCs is likely to play a part in that space. Engineering and related subjects will also be part of that demand and it is therefore important the more research is undertaken to find a mechanism to develop well-formed groups in MOOCs, so that future students can benefit from a structured approach to cooperative learning using tools and techniques such as CCD.

Teachonline [52] have identified 8 key changes for Program Design, and 7 key changes for Teaching and Learning, that we can expect to see in the immediate future, as online learning impacts across the sector:

\section{Program Design}

- More flexible program designs

- More use of open educational resources

- More creative assessment processes

- More micro-credit and nano-degrees

- More co-op and experiential components within programs

- More international collaborative programs

$14^{\text {th }}$ LACCEI International Multi-Conference for Engineering, Education, and Technology: "Engineering Innovations for Global Sustainability", 20-22 July 2016, San José, Costa Rica. 
- More transfer and international recognition agreements

- Blurring of lines between College and University

\section{Teaching and Learning}

- Learning will no longer be defined by time, place or institutional offerings

- Learners will create their own learning agendas, which reflect their own career, personal and lifelong learning goals

- Learners will secure their learning outcomes through a combination of formal, informal, self-directed, instructor-delivered, in class and online learning

- Learners will expect personalized learning services and supports for their learning agenda

- New mechanisms for meeting personal learning agendas will appear in the marketplace as the "unbundling" of learning continues

- Courses will be less important than mentoring, coaching, counselling, advising and assessment

- Diverse and new forms of credentials will appear which reflect the varied needs of learners, employers, social agencies, innovation organizations and entrepreneurs.

The vast majority of higher education institutions will be engaged with some or all of these areas, and for many of us this reflects a process that has been going on for many years. However, the argument now is simple, this is no longer a movement, or isolated instances of good practice, but rather the culmination of the movement, requiring of us significant change across every aspect of higher education. Deciding how we will support our students in becoming successful collaborative learners in online courses is a key step forward.

\section{ACKNOWLEDGMENT}

We wish to acknowledge the European Commission for their funding of the dCCD-FLITE project (Reference number: 2010-1-NO1-LEO05-01839) and all our partners in the project [53].

\section{REFERENCES}

[1] EDUCASE, CAUDIT, JISC and SURF 2010. "The Future of Higher Education: Beyond the Campus".

[2] UNESCO Institute for Statistics, Global Education Digest, 2009. Comparing Education Statistics Across the World (Montreal: UNESCOUIS, 2009), p. 10, http://www.uis.unesco.org/template/pdf/ged/2009/GED_2009_EN.pdf.

[3] INTO: the global education partners. 2013. Global Demand: The market opportunity. http://www.into-corporate.com/higher-education/globaldemand-the-market-opportunity.aspx

[4] WSJ, 2015. The Wall Street Journal 26th April 2015 "The Future of College: It's Online".

[5] Hansman, C.A., 2001. Context-based adult learning. New directions for adult and continuing education, 2001(89), pp.43-52.

[6] Grudin, J., 1994. "Computer-Supported Cooperative Work: History and Focus". Computer 27 (5): 19-26. doi:10.1109/2.291294.
[7] McConnell, D., 2000. Implementing Computing Supported Cooperative Learning. Routledge, ISBN 9780749431358

[8] Stahl, G., Koschmann, T., \& Suthers, D, 2006. Computer-supported collaborative learning: An historical perspective. In R. K. Sawyer (Ed.), Cambridge handbook of the learning sciences (pp. 409-426). Cambridge, UK: Cambridge University Press.

[9] Lachlan MacKinnon and Liz Bacon "Developing next generation online learning systems to support high quality global Higher Education provision" Published in "Innovations in Technology Enhanced Learning" Cambridge Scholars Publishing, Publication Date: 01/03/2015. ISBN13:978-1-4438-6629-3. ISBN-10:1-4438-6629-6. http://www.cambridgescholars.com/innovations-in-technology-enhancedlearning

[10]Hachey, Alyse C.; Wladis, Claire W.; Conway, Katherine M. (2012). Is the Second Time the Charm? Investigating Trends in Online ReEnrollment, Retention and Success. Journal of Educators Online, v9 n1 Jan 2012.

[11]Felder, R.M. and Silverman, L.K., 1988. Learning and teaching styles in engineering education. Engineering education, 78(7), pp.674-681.

[12]Muesser Cemal Nat, Liz Bacon, Simon Walker, Prof. Mohammad Dastbaz. "Learning design approaches for personalised and nonpersonalised e-learning systems." Special edition of The Journal of Teaching English with Technology (TEwT): LAMS AND Learning Design. Vol 2, June 2011 pp 177-189. ISBN: 978-9963-634-95-8. Edited by: Chris Alexander, James Dalziel, Jaroslaw and Richard Keily.

[13]Jane E. Brindley, Christine Walti and Lisa M. Blaschke. June 2009. "Creating Effective Collaborative Learning Groups in an Online Environment". The International Review of Research in Open and Distributed Learning, Vol 10, No 3 (2009).

[14]Driscoll, A., Jicha, K., Hunt, A.N., Tichavsky, L. and Thompson, G., 2012. Can online courses deliver in-class results? A comparison of student performance and satisfaction in an online versus a face-to-face introductory sociology course. Teaching Sociology, 40(4), pp.312-331.

[15]Khoo, Elaine, Forret, Michael and Cowie, Bronwen. (2010). LecturerStudent Views on Successful Online Learning Environments. Waikato Journal of Education 15, Issue 3: 2010.

[16]Artino, A.R. and Jones, K.D., 2012. Exploring the complex relations between achievement emotions and self-regulated learning behaviors in online learning.The Internet and Higher Education, 15(3), pp.170-175.

[17]Sonwalkar, N., 2013, September. The first adaptive MOOC: A case study on pedagogy framework and scalable cloud Architecture-Part I. In MOOCs Forum (Vol. 1, No. P, pp. 22-29). 140 Huguenot Street, 3rd Floor New Rochelle, NY 10801 USA: Mary Ann Liebert, Inc.

[18]Fisher, M. and Baird, D.E., 2005. Online learning design that fosters student support, self-regulation, and retention. Campus-Wide Information Systems,22(2), pp.88-107.

[19]Minerva project 2014. http://about.minervaproject.com/

[20]Bullingham, L. and Vasconcelos, A.C., 2013. 'The presentation of self in the online world': Goffman and the study of online identities. Journal of Information Science, 39(1), pp.101-112.

[21]Mishna, F., Saini, M. and Solomon, S., 2009. Ongoing and online: Children and youth's perceptions of cyber bullying. Children and Youth Services Review, 31(12), pp.1222-1228.

[22]Collis, B.A., 1994. Cooperative learning and CSCW: research perspectives for internetworked educational environments.

[23] Goodyear, P., Jones, C. and Thompson, K., 2014. Computer-supported collaborative learning: Instructional approaches, group processes and educational designs. In Handbook of research on educational communications and technology (pp. 439-451). Springer New York.

[24]Wang, S.L. and Hwang, G.J., 2012. The role of collective efficacy, cognitive quality, and task cohesion in computer-supported collaborative learning (CSCL). Computers \& Education, 58(2), pp.679-687.

[25]Noroozi, O., Weinberger, A., Biemans, H.J., Mulder, M. and Chizari, M., 2012. Argumentation-based computer supported collaborative learning (ABCSCL): a synthesis of 15 years of research. Educational Research Review, 7(2), pp.79-106.

[26]Palloff, R. and Pratt, K., 2005 (1), August. Online learning communities revisited. In 21 st Annual Conference on Distance Teaching and Learning.

$14^{\text {th }}$ LACCEI International Multi-Conference for Engineering, Education, and Technology: "Engineering Innovations for 
[27]Palloff, R. M., \& Pratt, K. 2005 (2). Collaborating online: Learning together in community. San Francisco, CA: Jossey-Bass.

[28]Meslec, N. and Curşeu, P.L., 2015. Are balanced groups better? Belbin roles in collaborative learning groups. Learning and Individual Differences, 39, pp.81-88.

[29]Belbin, M. (1981). Management teams, why they succeed or fail. London: Heinemann

[30]Jennifer Cowley, Sharon Chanley, Stephen Downes, Lisa Holstrom, Dawn Ressel, George Siemens, Mitchell Weisburgh, 8th Oct 2002. "Interaction". ELearning Course. Retrieved May 24 Jan, 2016, from: http://www.elearnspace.org/Articles/Interaction.htm

[31]Siemen, G. (2002). Interaction. E-Learning Course. October 8, 2002. Retrieved May 24 Jan, 2016, from http://www.elearnspace.org/Articles/Interaction.htm

[32]Popov, V., Brinkman, D., Biemans, H.J., Mulder, M., Kuznetsov, A. and Noroozi, O., 2012. Multicultural student group work in higher education: An explorative case study on challenges as perceived by students. International Journal of Intercultural Relations, 36(2), pp.302317.

[33]Guzdial, M., Ludovice, P., Realff, M., Morley, T., Carroll, K., and Ladak, A. (2001). The challenge of collaborative learning in engineering and math. In Proceedings of IEEE/ASEE Frontiers in Education (FIE) 2001 Conference. IEEE, Reno, NV.

[34]James J. Sharp (1991) Methodologies for problem solving: An engineering approach, The Vocational Aspect of Education, 42:114, 147 157, DOI: $10.1080 / 10408347308003631$

[35]Khazaal, H.F., 2015. Problem Solving Method Based On E-Learning System For Engineering Education. Journal of College Teaching \& Learning (TLC),12(1), pp.1-12.

[36] Weimer, Maryellen. 4th March 2015. "Different Types of Group Work: Clearing up the Confusion", Faculty Focus -

http://www.facultyfocus.com/articles/teaching-professor-blog/differenttypes-group-work-clearing-confusion/

[37] Beaven, T., Hauck, M., Comas-Quinn, A., Lewis, T. \& d.1.Arcos, B., (2014), MOOCs: Striking the Right Balance between Facilitation and Self-Determination, MERLOT Journal of Online Learning and Teaching, V. 10, N. 1, March 2014.

[38] Belbin, R.M., (2012), Team Roles at Work, books.google.com

[39] Teachonline (2016a). A 2016 Look at the Future of Online Learning Part 1. http://www.teachonline.ca/tools-trends/exploring- futureeducation/2016-look-future-online-learning- part-1

[40] McGill University, (2015), https://www.mcgill.ca/desautels/programs/grooc

[41] Poets \& Quants, (2015), "Enter the GROOC, better than a MOOC", http://poetsandquants.com/2015/01/04/enter-the-grooc-better-than-amooc/

[42] Doherty, E. Thornley, C., Carcary, M. Carcary, Mc Laughlin, S. Korte, W. Gareis, K. Kolding, M. Cattaneo, G., Fanning, F. Editos. 2014. "eSkills: The International Dimension and the Impact of Globalisation" Ref. Ares(2014)3126383 - 23/09/2014. Prepared for European Commission, Enterprise and Industry Directorate General

[43] CPHC 2012. "CS Graduate Unemployment Report 2012". https:/cphcuk.files.wordpress.com/2013/12/cs_graduate_unemployment report.pdf

[44]K-̄oft, M. Stiehler, F., Zheng, Z., Pinkwart, N. "Predicting MOOC dropout over weeks using machine learning methods." EMNLP 2014 (2014): 60.

[45] Muilenburg, L. Y., and Berge, Z. L. (2005). Student barriers to online learning: A factor analytic study. Distance Education 26, 1 (2005), 2948.

[46] Strand, K.A., \& Staupe, A. (2010). The concurrent e-learning design method. In Z. Abas et al. (Eds.), Proceedings of Global Learn Asia Pacific 2010. (pp. 4067-4076). Chesapeake, VA: AACE.

[47] Strand Knut Arne. Concurrent Design Approach to the Design of Customized Corporate E-Learning. PhD Thesis, Norwegian University of Science and Technology, Trondheim, November 2012.

[48] Stamatis, D. Hansson, B. Hjeltnes, TA, MacKinnon, L. (2015). A Distributed Concurrent Design based e-Learning approach to Entrepreneurship Education. Proceedings of ICEIRD 2015 (8th
International Conference for Entrepreneurship, Innovation and Regional Development, 18-19 June 2015, Sheffield, UK.

[49] Onah, Daniel F. O., Sinclair, Jane and Boyatt, Russell (2014) Dropout rates of massive open online courses : behavioural patterns. In: 6th International Conference on Education and New Learning Technologies, Barcelona, Spain, 7-9 Jul 2014. Published in: EDULEARN14 Proceedings pp. 5825-5834.

[50] Liz Bacon, Lachlan MacKinnon, Mark Anderson, Börje Hansson, Anne Fox, Mariano Cecowski, Tor Atle Hjeltnes, Demosthenes Stamatis. "Addressing retention and completion in MOOCs - a student-centric design approach". E-LEARN 2015 - World Conference on E-Learning, Kona, Hawaii: October 19-22, 2015.

[51] Mackness, Jenny, Sui Mak, and Roy Williams. "The ideals and reality of participating in a MOOC." (2010): 266-275.

[52] Teachonline (2016b). A 2016 Look at the Future of Online Learning Part 2. http://www.teachonline.ca/tools-trends/exploring- futureeducation/2016-look-future-online-learning- part-2

[53] FLITE (2015), "Flexible Learning in Technology and Entrepreneurship", www.ccdflite.eu/ 